\title{
CPC/2015 E A APLICAÇÃO DAS MEDIDAS ATÍPICAS NO PROCESSO DE EXECUÇÃO
}

Natália Alves de Santana, Carolina Mendes Mosaner, Caroline Regina da Silva

Universidade do Oeste Paulista Unoeste, Curso de Direito, Cidade Presidente Prudente, Estado de São Paulo. E-mail: nattalia.santana@hotmail.com

\section{RESUMO}

O presente artigo tem o escopo de analisar a aplicação das medidas atípicas do magistrado no processo de execução, sob a luz dos princípios constitucionais e processuais do nosso ordenamento jurídico. Tal possibilidade veio prevista no artigo 139, IV, do CPC/2015 e causou grande controvérsia entre os operadores do direito, uma vez que, há entendimento de que a aplicação de tais medidas fere os princípios da proporcionalidade e da razoabilidade, bem como, as garantias fundamentais previstas na Constituição Federal, como o direito de liberdade de locomoção. Em contrapartida, há entendimento de que tais medidas colaboram com a efetividade processual. Será analisada as possibilidades de aplicação de tais medidas, suas limitações, e quais seus fundamentos.

Palavras-chave: Processo Civil, Atipicidade, Coerção, Execução, Sanções típicas.

\section{CPC/2015 AND THE APPLYING OF ATYPICAL MEASURES IN EXECUTION PROCESS}

\begin{abstract}
This paper aims to analyze the possibility of applying atypical measures of the judge in execution process, under the light of constitucional priciples and the processual legal system. The possibility has been foreseen in the article 139, IV, of CPC/2015 and caused controversy among operators of law, since it is understood that the application of such measures violates the principles of proportionality and reasonableness, as well as the fundamental guarantees provided for in the Federal Constitution, such as the right to freedom of movement. On the other hand, it is understood that such measures collaborate with the procedural effectiveness. Will be analyzed the possibilities application of this measures, its limitations and its fundamentals.
\end{abstract}

Keywords: Civil Procedure, Atypicality, Coercion, Execution, Typical Sanctions. 


\section{INTRODUÇÃO}

Embora historicamente se dê superior importância ao processo de conhecimento por parte da doutrina e do legislador, a prestação jurisdicional não encontra ainda nessa fase seu desfecho.

Contrariamente, encerrando-se a fase de conhecimento, vislumbra-se a necessidade de iniciar uma fase posterior a resolução do direito controvertido, onde se desenvolve a tutela executiva do direito pleiteado.

Com o advento do NCPC/2015 passou-se a olhar com mais atenção a questão da efetividade de tal tutela executiva, principalmente em razão da redação do artigo 139, IV, que confere amplos poderes para o magistrado agir na fase executiva de forma a compelir que a prestação devida seja efetivamente satisfeita pelo devedor.

Destarte, tal artigo ganhou caráter controvertido entre os operadores do direito, devido a sua amplitude, o que poderia ocasionar abusos por parte dos magistrados quando de sua aplicação.

Desde a edição do CPC/2015 muito já se discutiu o assunto pela doutrina e jurisprudência pátrias, no sentido de unificar um entendimento sobre sua aplicação e limites.

O objetivo deste trabalho foi analisar como se comportou os tribunais e os cientistas do direito no sentido de formarem um entendimento pacificado sobre o controverso dispositivo.

\section{METODOLOGIA}

A metodologia utilizada para elaboração do presente trabalho consistiu em pesquisa bibliográfica e consulta as legislações pertinentes, especialmente, a própria lei processual civil e a constituição federal, tal pesquisa inclui também a doutrina pátria, os enunciados elaborados nos fóruns e encontros processuais civis, além de julgados relevantes dos tribunais estaduais e superiores.

\section{RESULTADO}

Na busca da efetividade das decisões judiciais, o novo Código de Processo Civil expandiu os poderes do juiz na direção do processo. O artigo 139, inciso IV do CPC, prevê a atipicidade dos meios executivos como regra geral do sistema.

O código anterior já previa a possibilidade de aplicação de sanções típicas para garantir a obrigação de fazer e de não fazer, como, por exemplo, a imposição de astreintes. Com advento do $\mathrm{NCPC} / 2015$ o juiz pode adotar meios para assegurar o cumprimento das suas próprias ordens judiciais, sendo permitido ao magistrado "determinar todas as medidas indutivas, coercitivas, mandamentais ou sub-rogatórias necessárias para assegurar o cumprimento de ordem judicial, inclusive nas ações que tenham por objeto prestação pecuniária".

A indagação que tem gerado proeminente polêmica no meio jurídico, decorre de decisões que utilizam medidas indutivas atípicas, tais como suspensão da Carteira Nacional de Habilitação $\mathrm{CNH}$, cancelamento de cartões de crédito, restrição ao passaporte, entre outros, até que seja efetivamente comprovado o pagamento do débito gerador da lide.

Tais situações, produzem controvérsia no âmbito dos Tribunais, isso porque, alguns entendem que o poder atípico do juiz é uma nova sistemática executiva, enquanto outros a veem como uma possibilidade de adoção de medida arbitrária para restringir direitos e garantias fundamentais. Veja tenra decisão proferida pelo Poder Judiciário do Estado de São Paulo, nos autos do processo no 4001386-13.2013.8.26.0011 (2a Vara Cível do Foro Regional de Pinheiros). Assim pronunciou-se a eminente magistrada:

"(...) O processo tramita desde 2013 sem que qualquer valor tenha sido pago ao exequente. Todas as medidas executivas cabíveis foram tomadas, sendo que o executado não paga a dívida, não indica bens à penhora, não faz proposta de acordo e sequer cumpre de forma adequada as ordens judiciais, frustrando a execução. Se o 
executado não tem como solver a presente dívida, também não recursos para viagens internacionais, ou para manter um veículo, ou mesmo manter um cartão de crédito. Se, porém, mantiver tais atividades, poderá quitar a dívida, razão pela qual a medida coercitiva poderá se mostrar efetiva."

Em seguida, o próprio Tribunal Judicial de São Paulo suspendeu a decisão de primeira instância sob a alegação de que a coação seria ilegal, pois afeta direito fundamental previsto no artigo 5o da CF.

A par disso, anoto que a jurisprudência pátria vem entendendo que a aplicação de tais medidas deve ser feita de forma subsidiária. Nesse sentido, a recente decisão proferida pelo $\mathrm{E}$. Superior Tribunal de Justiça:

"AGRAVO DE INSTRUMENTO. AÇÃO DE EXECUÇÃO. TÍTULO JUDICIAL. ADOÇÃO DE MEDIDAS EXECUTIVAS ATÍPICAS FUNDADAS NO ART. 139, IV, DO CPC/2015. NÃO CABIMENTO. EXISTÊNCIA DE MEDIDAS EXECUTIVAS TÍPICAS. CARÁTER SUBSIDIÁRIO DAQUELAS EM RELAÇÃO A ESTAS. RECURSO PARCIALMENTE PROVIDO. As medidas executivas fundadas no art. $139, I V$, do CPC/2015, em razão de sua atipicidade, devem ser adotadas excepcionalmente, de forma subsidiária àquelas típicas já previstas no ordenamento jurídico. É dizer, só devem ser utilizadas após esgotados todos os meios tradicionais de execução, de forma subsidiária".

(TJSP - Agravo de Instrumento: Al 20175118420178260000 SP 201751184.2017.8.26.0000. Órgão Julgador 31 a Câmara de Direito Privado. Publicação 11/04/2017. Julgamento 11 de Abril de 2017. Relator Adilson de Araújo).

Nesta toada, decisão também proferida pelo Tribunal de Justiça de São Paulo:

AGRAVO DE INSTRUMENTO. EXECUÇÃO DE SENTENÇA. DECISÃO QUE APLICOU MEDIDAS ATÍPICAS DE APREENSÃO DAS CARTEIRAS DE HABILITAÇÃO E DOS PASSAPORTES DOS SÓCIOS DA EMPRESA EXECUTADA, NA FORMA DO ARTIGO 139, IV, DO CÓDIGO DE PROCESSO CIVIL. As medidas atípicas, previstas no artigo 139, IV, do Código de Processo Civil, são excepcionais e só devem ser aplicadas quando as medidas típicas, como a penhora, a expropriação e o arresto de bens, forem esgotadas e se mostrarem ineptas para a satisfação do direito do exequente. São medidas de pressão psicológica que devem ser aplicadas quando se mostrarem potencialmente eficazes para que a satisfação da obrigação ocorra, ou seja, especialmente quando se provar que o executado não paga porque não quer ou porque está tentando fraudar a execução, blindando o seu patrimônio. (...) Apesar de ser claro o direito fundamental do exequente em obter a tutela jurisdicional efetiva para a satisfação de seu crédito deve-se levar em conta, em cada caso concreto, a proporcionalidade e a razoabilidade das medidas a serem aplicadas, escolhendo, primordialmente, os meios executivos que gerem a menor onerosidade ao executado. (...) Recurso CONHECIDO e PROVIDO.

(TJ-RJ - Al: 00532037620178190000 RIO DE JANEIRO CAPITAL 48 VARA CIVEL, Relator: CEZAR AUGUSTO RODRIGUES COSTA, Data de Julgamento: 06/03/2018, OITAVA CÂMARA CÍVEL, Data de Publicação: 08/03/2018).

Sobre a possibilidade de aplicação de medidas coercitivas, preceitua Marcus Vinicius Rios Gonçalves, mestre em Direito Civil pela PUCSP:

“(...) Como a lei não faz nenhuma ressalva, parece-nos que todas as medidas coercitivas ou sub-rogatórias previstas para as obrigações de fazer ou não fazer estendemse às obrigações por quantia, inclusive a relativa ao pagamento de multa diária (astreintes), o que, de maneira geral, não era admitido na legislação anterior. Porém, a imposição de meios coercitivos, como a multa, nas obrigações por quantia certa deverá ser de aplicação 
excepcional ou subsidiária, quando os meios de sub-rogação não forem eficazes". (GOLÇALVES, 2016).

Para MEDINA (2017) a utilização de tais poderes pelo Magistrado deve sempre vir acompanhado de uma interpretação estritamente constitucional e poderão ser usados de maneira mais ou menos gravosa dado o bem jurídico tutelado.

GONÇALVES (2016) entende que o uso de tais poderes deve se restringir as hipóteses de esgotamento dos meios tipicamente previstos e dada sua utilidade e efetividade em produzir resultado útil ao processo.

$\mathrm{Na}$ tentativa de suprir as lacunas de interpretação do dispositivo, redigiu-se enunciados sobre o tema com o escopo de elucidar as discussões acerca do tema.

O enunciado 12 do Fórum Permanente de Processualistas Civis tenta elucidar a interpretação para a aplicação do referido dispositivo de lei:

"A aplicação das medidas atípicas sub-rogatórias e coercitivas é cabível em qualquer obrigação no cumprimento de sentença ou execução de título executivo extrajudicial. Essas medidas, contudo, serão aplicadas de forma subsidiária às medidas tipificadas, com observação do contraditório, ainda que diferido, e por meio de decisão à luz do art. 489, \& 1ㅇ, I e II".

O enunciado 396 (FPPC) suplementa ainda o tema dizendo:

"As medidas do inciso IV do art. 139 podem ser determinadas de ofício, observado o art. 8‥"

O citado artigo 8o prevê que:

Ao aplicar o ordenamento jurídico, o juiz atenderá aos fins sociais e às exigências do bem comum, resguardando e promovendo a dignidade da pessoa humana e observando a proporcionalidade, a razoabilidade, a legalidade, a publicidade e a eficiência.

A ENFAM também redigiu enunciado sobre o tema, dizendo:

"O art. 139, IV, do CPC/2015 traduz um poder geral de efetivação, permitindo a aplicação de medidas atípicas para garantir o cumprimento de qualquer ordem judicial, inclusive no âmbito do cumprimento de sentença e no processo de execução baseado em títulos extrajudiciais."

Tal enunciado trata de elucidar a amplitude do referido dispositivo que aplica-se para "garantir o cumprimento de qualquer ordem judicial", ampliando assim ainda mais a importância de tais poderes frente uma tutela jurisdicional pulsante por efetividade.

\section{DISCUSSÃO}

Visualiza-se que não obstante os três anos de aplicação do Código de Processo Civil de 2015, ainda se tem muitas questões em aberto, o artigo 139, IV, que foi uma das maiores revoluções do código é ainda hoje um dos pontos mais relevantes a se elucidar, principalmente devido sua amplitude que deve ser interpretada de forma a se manter a segurança jurídica na tutela jurisdicional executiva, de forma a não chegar tais poderes a constituírem mera arbitrariedade do magistrado.

No entanto, grande problema se encontra quando se discute, a exemplo, o confronte de um bem jurídico de ordem patrimonial com direitos fundamentais e até que ponto seria justo, ou não, entrar na esfera da liberdade do indivíduo para cobrar a tutela de bens relacionados a direitos de menor ordem, como o patrimônio. 
A doutrina e jurisprudência pátrias, têm-se entendido no sentido de que a aplicação de tais poderes só poderá ocorrer em caráter subsidiário as medidas tipicamente previstas; com a observância do devido contraditório; e fundamentando a decisão sob o aspecto da proporcionalidade da medida ao bem da vida que se quer tutelar e a efetividade de tal medida.

Destarte, os mesmos comandos se extraem do texto do enunciado 12 da FPPC: a) as medidas atípicas deverão ser sempre subsidiárias às medidas típicas; b) Tais medidas poderão ser usadas no cumprimento de sentença de qualquer tipo e natureza de obrigação; c) Deverá sempre ter-se observado contraditório; d) A decisão deve ser fundamentada.

Parece-nos ainda claro que o legislador quis manter em aberto a possibilidade do uso de tais medidas em cumprimento de sentença de qualquer natureza.

O contraditório dado que é principio base de qualquer pretensão resistida, deve estar também presente quando da aplicação de tais medidas.

E finalmente, o Juiz deverá sempre fundamentar de forma a consubstanciar na decisão o binômio da adequação e necessidades e de maneira a não confrontar direitos fundamentais e o princípio da proporcionalidade.

Tais parâmetros quando aplicados a interpretação do dispositivo de lei faz dele instrumento apto a tornar a tutela jurisdicional executiva mais justa e efetiva.

\section{CONCLUSÃO}

Conclui-se, portanto, que os poderes atípicos do juiz devem ser necessariamente subsidiários às medidas típicas, sendo assim, estas devem funcionar como uma espécie de "ultima ratio" da tutela executiva cível usada pelo Juiz sempre visando à efetiva satisfação da pretensão resistida e nunca por mera punição.

\section{REFERÊNCIAS}

BRASIL. Constituição (1988). Constituição da República Federativa do Brasil. Brasília, DF: Senado Federal;

BRASIL. Código de processo civil (2015). Lei n.13.105, de março de 2015. Brasília, DF: Senado Federal;

DIDIER Jr., Fredie; SCARPINELLA, BUENO, Cassio; BASTOS, Antônio Adonias. "Carta de Salvador - II Encontro dos Jovens Processualistas do Instituto Brasileiro de Direito Processual (IBDP)". Revista de Processo. São Paulo: RT, 2014, v. 227, p. 435-437;

GOLÇALVES, Marcus Vinicius Rios. Direito Processual Civil Esquematizado - 7. Ed. - São Paulo: Saraiva, 2016;

MEDINA, José Miguel Garcia. Execução - Teoria Geral, Princípios Fundamentais, Procedimento No Processo - 5a Ed. - São Paulo: RT, 2017. 